University of Louisville

ThinkIR: The University of Louisville's Institutional Repository

Faculty Scholarship

$11-2015$

\title{
Teaching Behavior Questionnaire : verifying factor structure and investigating depressive symptoms in Catholic middle and high schools.
}

\author{
Caroline M. Pittard \\ University of Louisville \\ Patrick Pössel \\ University of Louisville \\ Rosamond J. Smith \\ University of Louisville
}

Follow this and additional works at: https://ir.library.louisville.edu/faculty

Part of the Counseling Psychology Commons, and the Educational Psychology Commons

Original Publication Information

This is the peer-reviewed version of the following article:

Pittard, Catherine M., Patrick Pössel and Rosamond J. Smith. "Teaching Behavior Questionnaire: Verifying Factor Structure and Investigating Depressive Symptoms in Catholic Middle and High Schools." 2015.

Psychology in the Schools 52(9): 892-905.

which was published in final form at http://doi.org/10.1002/pits. 21865

This article may be used for non-commercial purposes in accordance with Wiley Terms and Conditions for Self-Archiving.

This Article is brought to you for free and open access by ThinkIR: The University of Louisville's Institutional Repository. It has been accepted for inclusion in Faculty Scholarship by an authorized administrator of ThinkIR: The University of Louisville's Institutional Repository. For more information, please contact thinkir@louisville.edu. 
Teaching Behavior Questionnaire: Verifying Factor Structure and Investigating Depressive Symptoms in Catholic Middle and High Schools

Caroline M. Pittard, Patrick Pössel, and Rosamond J. Smith

Department of Educational and Counseling Psychology, Counseling, and College Student Personnel, University of Louisville, Louisville, KY, USA

Corresponding author:

Patrick Pössel, Dr. rer. soc.

Dep. of Educational and Counseling Psychology, Counseling, and College Student Personnel University of Louisville

2301 S. Third Street

Louisville, KY 40292

USA

+1-(502)852-0623 (office)

+1-(502)852-0629 (fax)

e-mail: patrick.possel@louisville.edu 


\begin{abstract}
Teaching behavior impacts student psychopathology. This study explored the associations between teaching behavior types and depressive symptoms in students. The Teaching Behavior Questionnaire (TBQ) and the Center for Epidemiological Studies - Depression Scale (CES-D) were completed by 763 middle and 976 high school students from private Catholic schools. In the middle school sample, a confirmatory factor analysis confirmed the four-factor structure of the TBQ previously found in public high schools. As predicted, a two-level hierarchical linear model (HLM) analysis with the high school sample found that only the Negative Teaching Behavior scale of the TBQ was positively related to CES-D scores, $(p<.05)$. A separate two-level HLM analysis with middle school students found the Instructional Behavior scale was negatively related to CES-D scores $(p<.05)$ and the Organizational Behavior scale was positively related to the CES-D scores $(p<.01)$. Implications of the findings for school personnel are discussed.
\end{abstract}

Keywords: adolescence, teaching behavior, depressive symptoms, self-report, high school, middle school 
Teaching Behavior Questionnaire: Verifying Factor Structure and Investigating Depressive Symptoms in Catholic Middle and High Schools

Major depression, and even so-called "sub-syndromal depression" often begins during the adolescent years and is associated with risk for recurring depressive episodes throughout life (Georgiades, Lewinsohn, Monroe, \& Seeley, 2006; Rutter, Caspi, \& Moffitt, 2003). For example, about $9 \%$ of youth experience at least one depressive episode by the age of 14 (Abela \& Hankin, 2008; Mash \& Barkley, 2006), and this number increases to approximately $20 \%$ by the age of 18 (Hankin et al., 1998). The tripartite model of emotion (Clark \& Watson, 1991) characterizes depression as the combination of high negative affect and low positive affect. Thus, according to this model it can be helpful to consider positive and negative affect when investigating depression. One example of how affect expression is important in the classroom and therefore for school psychologists is the finding that higher levels of negative affect expressed by students and teachers in the classroom are associated with lower student achievement (for a review, see Soar \& Soar, 1987). Episodes of depression increase the chances of experiencing psychosocial problems including suicide attempts, substance abuse, interpersonal problems, and unemployment. The likelihood of experiencing academic problems also increases, including greater difficulty concentrating in class, lower rates of post-secondary degree attainment, poorer class attendance, reduced homework completion, and even academic failure (Humensky et al., 2010; Jonsson et al., 2010; Klein, Torpey, \& Bufferd, 2008). Thus, affect in general and depression in particular are relevant for psychologists working in school settings.

Thus, the high depression rates by the age of 14 years (Abela \& Hankin, 2008; Mash \& Barkley, 2006) and even higher depression rates by the age of 18 years (Hankin et al., 1998) demonstrate that depression is problematic during middle school and becomes even more of a problem during high school. This notion is further supported by stressful life 
transitions that occur during adolescence, namely, school transitions. As school psychologists know, when beginning middle school, students are entering learning environments that are often larger, less nurturing, and less focused on teacher-student relationships than elementary schools (Barber \& Olsen, 2004; Blyth, Simmons, \& CarltonFord, 1983; Lynch \& Cicchetti, 1997; Roeser \& Eccles, 1998). High schools follow this trend and are often even larger and less focused on teacher-student relationships than middle schools (Eccles, Midgley, \& Adler, 1994). In fact, the transition into larger, more anonymous school settings is often accompanied by decreased academic interest and performance as well as increased depressive symptoms (Barber \& Olsen, 2004).

\section{Teacher Support and Student Outcomes}

Given the fact that young people spend about 15,000 hours of their lives in schools and the majority of this time under the supervision of teachers (Rutter, 1982), it is not surprising for many psychologists working in schools that teacher support impacts a variety of student academic and psychosocial variables, as well as psychopathology. Related to academic achievement, middle school students reporting greater teacher support were more likely to collaborate with their peers on problems, working together to increase their learning, rather than just asking for answers (Ryan \& Shim, 2012). In a longitudinal study of students in $3^{\text {rd }}$ through $6^{\text {th }}$ grade, students who felt that they were important to their teachers reported feeling more comfortable and happy in class, compared to students who reported feeling unimportant to their teachers (Furrer \& Skinner, 2003). Additionally, middle and high school students rating their teachers as less supportive reported lower self-esteem (Reddy, Rhodes, \& Mullhall, 2003; Roeser \& Eccles, 1998; Ryan, Stiller, \& Lynch, 1994), higher selfconsciousness (Roeser, Midgeley \& Urdan, 1996), and more depressive symptoms compared to students who did perceive support from teachers (Cheung, 1995; Pössel, Rudasill, Sawyer, Spence, \& Bjerg, 2013; Reddy et al., 2003; Roeser \& Eccles, 1998). Thus, middle and high 
school contexts seem to be crucial for teacher support due to their influence on academic and psychosocial outcomes and psychopathology.

\section{Specific Teaching Behaviors}

Within the construct of teacher support lie specific categories of teaching behaviors: (positive) instructional, organizational, socio-emotional, and negative teaching behaviors (Connor et al., 2009; Douglas, 2009; Pianta \& Hamre, 2009; Pössel, Rudasill, Adelson, Bjerg, Wooldridge, \& Winkeljohn Black, 2013). Academic and social outcomes as well as psychopathological symptoms (e.g., Hamre \& Pianta, 2005; Perry, Donohue, \& Weinstein, 2007; Pössel, Rudasill, Sawyer, et al., 2013) are related to these categories of teaching behavior.

\section{(Positive) Instructional Teaching Behavior}

(Positive) instructional teaching behavior promotes critical thinking, development of skills, understanding of concepts, and is used during the delivery of instruction (Croninger \& Valli, 2009; Pianta, LaParo, \& Hamre, 2008). This type of teaching behavior includes providing opportunities for students to receive positive feedback, respond to questions and prompts, and choose answers. (Positive) instructional teaching behavior encourages achievement in the classroom (Curby, Rudasill, Edwards, \& Perez-Edgar, 2011; Hamre \& Pianta, 2005; Rubie-Davies, 2007) and is negatively related to negative affect (Pössel, Rudasill, Adelson, et al., 2013).

The impact of (positive) instructional teaching behavior on academic variables seems to mediate the association of (positive) instructional teaching behavior with psychosocial variables and psychopathology. For example, (positive) instructional teaching behavior predicts students' academic competency (Curby et al., 2011; Hamre \& Pianta, 2005) and middle school students' academic competency predicts their grade point average, which is in turn related to levels of self-reported sadness and hopelessness (Roeser, Eccles, \& Sameroff, 
2000). The finding that (positive) instructional teaching behavior was negatively associated with negative affect in high school students further supports the associations of (positive) instructional teaching behavior with psychopathology (Pössel, Rudasill, Adelson, et al., 2013). In sum, the relationship between instructional teaching behavior and academic outcomes, coupled with the relationship between academic outcomes and psychopathological outcomes, lend support to the possibility that instructional teaching behavior is associated with psychopathological outcomes. However, no study thus far has directly examined the association between instructional teaching behavior and psychopathology in general or depressive symptoms in particular which leaves school psychologists without the empirical support they need to know the impact of (positive) instructional teaching behavior on the mental health of their students.

\section{Organizational Teaching Behavior}

Organizational teaching behavior refers to the teacher's facilitation of smooth transitions between activities, minimization of disruptions, and other measures put in place to use class time efficiently (Connor et al., 2009; Pianta \& Hamre, 2009). Organizational teaching behavior occurs when teachers ensure that students understand the rules and explain why misbehavior in the classroom is wrong (Connor et al., 2009; Pianta \& Hamre, 2009). This type of teaching behavior is associated with more productive use of class time (Cameron, Connor, \& Morrison, 2005) and increased student engagement and learning (Bohn, Roehrig, \& Pressley, 2004; Rimm-Kaufman et al., 2010). Additionally, Rubie-Davies (2007) found that students who made significant gains in academic achievement over the course of one school year had teachers that used more organizational teaching behavior than teachers of students who made no significant or negative gains. As organizational teaching behavior has been negatively associated with negative affect in high school students (Pössel, Rudasill, Adelson, et al., 2013), as far as we know, no study thus far has directly examined 
the association between organizational teaching behavior and psychopathology in general or depressive symptoms in particular. Thus, school psychologists lack empirical data that would allow them to decide whether interventions regarding organizational teaching behavior would be beneficial when considering the mental health of their students.

\section{Socio-emotional Teaching Behavior}

Socio-emotional teaching behavior is evidenced by responsiveness and warmth when interacting with students. It can be present at any time, and it encourages students' feelings of acceptance and belongingness in the classroom. Research findings show that socio-emotional teaching behavior is positively associated with increased academic achievement (e.g., Hamre \& Pianta, 2005; Rudasill, Gallagher, \& White, 2010) as well as is positively associated with both positive and negative affect (Pössel, Rudasill, Adelson, et al., 2013). Thus, it has clear relevance for school psychologists. To add to these findings, Pössel, Rudasill, Sawyer, et al. (2013) found that emotional support by teachers, a type of socio-emotional teaching behavior, predicted a reduction of depressive symptoms in high school students with high numbers of stressful life events, while it predicted an increase of depressive symptoms in students with low numbers of stressful life events. Thus, the association of socio-emotional teaching behavior with affect and depressive symptoms in students seems more complicated than one might expect.

The authors of both studies (Pössel, Rudasill, Adelson, et al., 2013; Pössel, Rudasill, Sawyer, et al., 2013) provide two possible explanations for their unexpected finding. First, they argue that the positive relationship between socio-emotional teaching behavior and student depressive symptoms may be caused by students who are in a negative emotional state, as those students may seek and report more socio-emotional support from their teachers than other students. Second, the authors hypothesize that this association may be explained by the deviancy training hypothesis. According to this, students are role models for each 
other for affect, learning to attend to or describe negative affect from one another. This could mean that socio-emotional teaching behavior provides a safe space for such learning as it allows students to express their negative affect in the classroom. Overall, these findings are evidence that socio-emotional teaching behavior may not be associated with depressive symptoms for all students.

\section{Negative Teaching Behavior}

Negative teaching behavior is counter-productive behavior that is unpleasant for students, such as threatening students with punishments, being easily provoked, or being inconsistent (Pössel, Rudasill, Adelson, et al., 2013). Inconsistent behavior includes a teacher not following through with consequences for disruptive behavior, based on his or her mood (Pössel, Rudasill, Adelson, et al., 2013). This kind of teaching behavior creates a negative academic and emotional climate in the classroom (Pianta \& Hamre, 2009) which is associated with both psychosocial variables and psychopathology. For example, in a study of grade 6 students and their teachers, teacher-reported negative classroom climate was related to teacher-reported depressive symptoms in students (Somersalo, Solantaus, \& Almqvist, 2002). In another study of grade 6 students, Wentzel (2002) found that giving students negative feedback such as criticisms, was related to decreased academic achievement, which is related to negative affect expressed in the classroom (for a review, see Soar \& Soar, 1987). Additionally, a study of high school students found that negative teaching behavior was positively associated with negative affect and negatively associated with positive affect (Pössel, Rudasill, Adelson, et al., 2013). However, no study thus far has directly examined the association between negative teaching behavior and psychopathology in general or depressive symptoms in particular.

Summarized, students spend a large amount of time under the supervision of teachers (Rutter, 1982). Thus, it is probably not surprising to most school psychologists that teacher 
support is negatively associated with depressive symptoms in students (e.g., Pössel, Rudasill, Sawyer, et al., 2013). However, as far as we know, no study has tested for associations between concrete, specific, and most importantly, changeable teaching behaviors and students' depressive symptoms. This is relevant as the identification of such associations may be used by psychologists working in school settings to prevent depression in students by changing teaching behavior.

\section{Social and Abstract Reasoning}

It is not new to school psychologists that students' social reasoning skills develop during middle and high school, and are thus especially relevant to students' understanding and perception of their teachers' behaviors in the classroom (Hatcher, Hatcher, Berlin, Okla, \& Richards, 1990; Marini \& Case, 1994). Marini and Case (1994) demonstrated that children's and adolescents' abstract social reasoning ability improves with increasing age, with participants in grade 10 completing more complex social reasoning tasks than participants in grade 7. Additionally, Hatcher et al. (1990) found that students' abstract reasoning and understanding of others increased with age, with significant gains from grade 8 to grade 12. To date, no studies have measured the relationship between depressive symptoms and teaching behavior in grade levels other than high school. Based on the described differences in social and abstract reasoning in middle and high school students, it is possible that the internal structure of student-rated teaching behavior differs between middle and high school students. Further, it is possible that the individual categories of teaching behavior are perceived differently and thus associated differently with depressive symptoms depending on student age and cognitive development. Thus, it is important for school psychologists in middle schools to examine teaching behavior and depressive symptoms across these age groups.

\section{The Current Study}


The purpose of the present study is to investigate the associations between (positive) instructional, organizational, socio-emotional, and negative teaching behavior with depressive symptoms in middle and high school students. Based on differences in cognitive development between middle and high school (Hatcher et al., 1990; Marini \& Case, 1994), it is possible that the factorial structure of student-rated teaching behavior for middle school students is different from the four-factor model previously determined with high school students (Pössel, Rudasill, Adelson, et al., 2013). Thus, three models of teaching behavior will be calculated and compared to determine the best fitting model with middle school students: (a) a model consistent with the four categories of teaching behavior described above; (b) a three factor model consistent with the theories of teaching behavior following Connor et al. (2009), Douglas (2009), and Pianta and Hamre (2009); and (c) a model with only one factor, assuming that the factors correlate so highly that they should not be separated. While differences in the cognitive development between middle and high school students may result in a different factorial structure of students' perception of teaching behavior, we lack substantial evidence to make this claim. This is particularly true as teaching behavior is observable and more specific than social reasoning and understanding of others. Thus, we expect to identify the four categories of teaching behavior ([positive] instructional, organizational, socio-emotional, and negative) in the middle school sample. It is expected that the four-factor model will be the best fit.

Following the tripartite model of emotion, the absence of positive affect and high negative affect are typical for depression (Clark \& Watson, 1991). Thus, findings of associations between the individual categories of teaching behavior and positive and negative affect in students (Pössel, Rudasill, Adelson, et al., 2013) can be used to inform hypotheses about associations between teaching behavior and depressive symptoms. Based on the described findings that negative teaching behavior is negatively associated with positive 
affect and positively associated with negative affect in high school students (Pössel, Rudasill, Adelson, et al., 2013), we expect that negative teaching behavior is positively associated with depressive symptoms in high school students. Further, as (positive) instructional and organizational teaching behavior have been negatively associated with negative affect but not significantly associated with positive affect in high school students (Pössel, Rudasill, Adelson, et al., 2013), it is not as clear if these two categories of teaching behavior are significantly associated with depressive symptoms. Nevertheless, we hypothesize they will be negatively associated with depressive symptoms in high school students, based on previous research (Humensky et al., 2010; Pössel, Rudasill, Adelson, et al., 2013; Roeser et al., 2000; Rubie-Davies, 2007). Finally, socio-emotional teaching behavior was unexpectedly positively associated with both positive and negative affect in high school students (Pössel, Rudasill, Adelson, et al., 2013). Thus, one could propose that the positive associations of socio-emotional teaching behavior with both positive and negative affect cancel each other out and no significant association between socio-emotional teaching behavior and depressive symptoms will emerge in high school students. As depressive symptoms require low positive affect and high negative affect, we propose that there will be no relationship between socio-emotional teaching behavior and depressive symptoms in high school students.

Finally, based on the previously mentioned research regarding changes in social reasoning and understanding of others as students progress through adolescence (Hatcher et al., 1990; Marini \& Case, 1994), we hypothesize that the associations between the individual categories of teaching behavior and depressive symptoms may be different in middle school students from the associations in high school students. However, there does not appear to be any specific empirical data supporting either of these two propositions, as the present study is the first one directly investigating these associations in middle school students. Thus, we 
propose that there will be a difference between middle school and high school students with regard to the associations of teaching behavior and depressive symptoms, but we do not have enough empirical evidence to predict where these differences will lie.

\section{Methods}

\section{Participants}

Four private Catholic/parochial high schools and five private Catholic/parochial middle schools were invited to participate in this study. There were no exclusion criteria and students did not receive any incentive for their participation.

Across the four high schools, 1085 students were invited to participate. Of those students, 976 students participated after receiving parent consent (participation rate $=$ 89.95\%). Further, 26 teachers volunteered to participate in this study. Of the participating students, $51.8 \%$ identified as female and $48.8 \%$ identified as male. Per student report, $92.6 \%$ of the students identified as Caucasian, $2.5 \%$ as African-American, $1.9 \%$ as other or multirace/ethnicity, $1.0 \%$ as Asian/Pacific Islander or as Hispanic, and 0.6\% as American Indian/Alaskan Native. Of the participating students, $37.5 \%$ stated that they were in $9^{\text {th }}$ grade, $26.4 \%$ in $10^{\text {th }}$ grade, $21.3 \%$ in $11^{\text {th }}$ grade, and $14.8 \%$ in $12^{\text {th }}$ grade, with a mean age of $15.52(S D=1.56)$. Of the students in the participating high schools, $8.9 \%$ were eligible for free or reduced lunch.

Across the five middle schools, 1018 students were invited to participate. Of those students, 763 students participated after receiving parent consent (participation rate $=$ $74.95 \%)$. Further, 28 teachers volunteered to participate in this study. Of the participating students, $58.4 \%$ identified as female and $41.3 \%$ identified as male. Per student report, $93.8 \%$ of the students identified as Caucasian, $2.0 \%$ as other or multi race/ethnicity, $1.7 \%$ as Asian/Pacific Islander, $1.3 \%$ as African-American, $0.9 \%$ as Hispanic, and $0.1 \%$ as American Indian/Alaskan Native. Of the participating students, $28.5 \%$ stated they were in $6^{\text {th }}$ grade, 
$34.7 \%$ in $7^{\text {th }}$ grade, and $24.3 \%$ in $8^{\text {th }}$ grade, with a mean age of $12.68(S D=1.25)$. Of the students in the participating schools, $9.1 \%$ were eligible for free or reduced lunch.

\section{Measures}

Teaching Behavior Questionnaire (TBQ). Pössel, Rudasill, Adelson, et al. (2013) used two independent samples of students in public high schools to develop the Teaching Behavior Questionnaire (TBQ), which measures student-reported teaching behavior. Based on an exploratory (EFA) and a confirmatory factor analysis (CFA) with these high school samples, the TBQ includes four specific behavior types: (Positive) Instructional Behavior (13 items; e.g. "My teacher uses examples that I understand," and "My teacher's grade requirements are clear"); Negative Teaching Behavior (9 items; e.g. "My teacher threatens to punish me when I misbehave"); Socio-Emotional Behavior (10 items; e.g. "My teacher talks with me about my interests"); and Organizational Behavior (5 items; e.g. "My teacher takes away a privilege if I abuse it"). Self-report responses are indicated on a four-point scale (from $1=$ never, to $4=$ always) and the scores of the four TBQ scales are calculated by averaging the item scores for each individual scale. Thus, low scores on subscales of the TBQ indicate a lower frequency of teaching behaviors of that type. High scores on subscales of the TBQ indicate a higher frequency of teaching behaviors of that type. Internal consistencies and correlations with TBQ scales as well as descriptive statistics can be seen in Table 1.

Center for Epidemiologic Studies - Depression Scale (CES - D). Radloff (1977) developed the Center for Epidemiological Studies - Depression Scale (CES - D) as a quickly administered, economical screening instrument to measure current depressive symptoms based on self-reports. The CES-D has been repeatedly administered to youths (e.g., Roberts, Andrews, Lewinsohn, \& Hops, 1990). The CES-D consists of 20 items (e.g., "During the past week, there were things that upset me that usually do not upset me"). Frequency of 
symptoms is rated on a four-point scale (from $0=$ rarely or none of the time to $3=$ most or all of the time). Item values are summed, creating a range from 0 to 60 for the final score. Scores of 16 or greater are generally used to indicate a clinically significant level of depressive symptoms. Internal consistencies and correlations with TBQ scales as well as descriptive statistics can be seen in Table 1.

\section{Procedure}

After the university's Institutional Review Board approved the study, the study was described to teachers during faculty meetings, and consent forms were collected. Then, letters describing the study were sent to parents of all students in the participating schools. Students who had parental consent were invited to participate. Student assent forms were collected at the beginning of the class periods in which the questionnaires were administered. Psychometric data were gathered via group administration during school hours. The TBQ and the CES-D were part of a questionnaire package administered to students that also included demographic information such as age, gender, and race/ethnicity. Students were asked to complete the TBQ according to the behavior of their English/Language Arts teacher (these teachers were not in the classrooms during assessment administration). Specifically, English/Language Arts teachers were chosen to participate in the study because English/Language Arts was a course that all students would have at all grade levels across all schools that participated.

\section{Statistical Analyses}

In order to test how well the four-factor model of (Positive) Instructional, Organizational, Socio-emotional, and Negative Teaching Behavior scales found in high school students applies to middle school students, confirmatory factor analyses (CFA) were performed on the middle school responses to the TBQ with the maximum likelihood method using IBM Amos 21. In addition to the model with the four correlated factors found in high 
school students, a one-factor and a three-factor model were tested. The goodness of fit of the models was evaluated with the $\chi^{2}$ statistic, Comparative Fit Index (CFI; Bentler, 1990), Normed-Fit Index (NFI; Bentler \& Bonnet, 1980), and root mean squared error of approximation (RMSEA; Steiger \& Lind, 1980). A fit of the model to the data is indicated by statistically non-significant values of $\chi^{2}$ (Kline, 2005; Ullman, 1996). CFI and NFI values should be $\geq .95$ for a good model fit and $\geq .90$ for an acceptable fit (Hu \& Bentler, 1999). A good model fit is also indicated by an RMSEA value of .05 and an acceptable fit is indicated by values of .08 (Hu \& Bentler, 1999). To compare models, $\Delta \mathrm{CFI}$ is calculated by subtracting the CFI values of the models from each other. When $\triangle \mathrm{CFI}$ is $>.002$ the model with higher CFI fits the data significantly better. However, when $\triangle \mathrm{CFI}$ is $\leq .002$ both models fit equally well from a statistical point of view and the more parsimonious model should be accepted (Meade, Johnson, \& Braddy, 2008). In addition, nested models were compared by subtracting the $\chi^{2}$ values as well as the $d f$ s of the models from each other ( $\chi^{2}$ difference tests). When $\Delta \chi^{2}$ is significant for $\Delta d f$, the models are seen as significantly different from each other.

To test for the proposed associations between teaching behavior and students' depressive symptoms, separate two-level hierarchical linear model (HLM) analyses for high school and middle school students were calculated using HLM version 6.07 (Raudenbush, Bryk, Cheong, Congdon, \& du Toit, 2004). In these analyses, all four types of studentreported teaching behavior were simultaneously entered as predictors of student-reported depressive symptoms with students nested in teachers.

\section{Results}

The four-factor model originally found in a high school sample (Pössel, Rudasill, Adelson, et al., 2013) $\left[\chi^{2}(623, N=763)=3676.30, p<.001\right.$, RMSEA (.080), CFI (.876), NFI (.855)], a one-factor model $\left[\chi^{2}(629, N=763)=7270.94, p<.001\right.$, RMSEA (.118), CFI 
(.730), NFI (.713)], and a three-factor model $\left[\chi^{2}(626, N=763)=5318.21, p<.001\right.$, RMSEA (.099), CFI (.810), NFI (.790)] were all calculated for the middle school sample. Like in the high school sample, only the RMSEA of the four-factor model was in the acceptable range, while the CFAs showed that none of the indices of goodness of fit for the other two models were in the acceptable range. Comparing the one- and the three-factor model with the fourfactor model using the $\triangle \mathrm{CFI}$ test revealed that the latter model fit the data of the TBQ in the sample of middle school students better than the other two models. This finding was confirmed by comparing the correlated four-factor model with the other models using $\chi^{2}$ difference tests [one-factor model: $\Delta \chi^{2}(6)=3594.64, p<.001$; three-factor model: $\Delta \chi^{2}(3)=$ 1641.91, $p<.001]$. In summary, the comparison of all three CFAs with the middle school sample confirmed the four-factor structure of the TBQ found previously with high school students.

Results of the regressions of depressive symptoms on teaching behavior can be seen in Table 2. Results in the high school sample showed that the TBQ Negative Teaching Behavior scale was positively associated with the CES-D scores $(p<.05)$ while no other TBQ scale was significantly associated with students' depressive symptoms. In the high school sample the TBQ explains $24.1 \%$ of the variance of the CES-D scores. In the middle school sample, the (Positive) Instructional Behavior scale was negatively related with the CES-D scores $(p<.05)$ and the Organizational Behavior scale was positively associated with CES-D scores $(p<.01)$. In this sample, the TBQ scales explain $17.1 \%$ of the variance of the CES-D scores.

\section{Discussion}

Considering the fact that students spend a large amount time under the supervision of teachers (Rutter, 1982), the main aims of this study were to verify the factor structure of the TBQ with a middle school sample and to investigate the associations between types of 
teaching behavior and students' depressive symptoms in Catholic middle and high school students. Both aims are relevant for school psychologists as the lack of empirical data prevents them from considering teaching behavior as factor impacting the mental health of students in their schools.

\section{Factor Structure of the TBQ}

The confirmatory factor analysis verified that the four-factor structure of the TBQ with the factors representing (positive) instructional, organizational, socio-emotional, and negative teaching behavior is the best fitting model for the middle school students. This is consistent with the factor structure previously found with high school students (Pössel, Rudasill, Adelson, et al., 2013). Thus, while social and abstract reasoning clearly develops during middle and high school (Hatcher et al., 1990; Marini \& Case, 1994), there is no evidence that this impacts the students' perception of teachers' behaviors in the classroom.

\section{Teaching Behavior and Depressive Symptoms in Catholic High School Students}

In the Catholic high school sample, negative teaching behavior is the only teaching behavior type to be significantly associated with depressive symptoms. This means that student reports of more negative teaching behavior, such as threatening to punish students, being easy to provoke, and not following through with consequences for misbehavior, are associated with more depressive symptoms in students. This finding is consistent with a previous study with public high school students, in which negative teaching behavior was positively associated with negative affect and negatively associated with positive affect (Pössel, Rudasill, Adelson, et al., 2013). In other words, both parts of depression, as postulated by the tripartite model of emotion (Clark \& Watson, 1991), were significantly associated with negative teaching behavior.

As expected, socio-emotional teaching behavior, which is evidenced by interactions with students that are warm and responsive, was not significantly associated with depressive 
symptoms in Catholic high school students. This is consistent with previous findings regarding the associations between socio-emotional teaching behavior and positive and negative affect in students from public high schools (Pössel, Rudasill, Adelson, et al., 2013). As socio-emotional teaching behavior was positively associated with both negative and positive affect, it was expected that these associations would cancel one another out when depressive symptoms are measured (Pössel, Rudasill, Adelson, et al., 2013). Thus, the lack of a significant association between socio-emotional teaching behavior and depressive symptoms confirms this hypothesis.

The null findings regarding (positive) instructional teaching behavior, which is behavior related to the delivery of instruction, and organizational teaching behavior, which is behavior related to classroom management, are not consistent with the study's hypotheses. They also depart from previous findings on these teaching behavior types and their associations with academic and psychosocial outcomes (Curby et al., 2011; Hamre \& Pianta, 2005; Humensky et al., 2010; Pössel, Rudasill, Adelson, et al., 2013; Roeser et al., 2000; Rubie-Davies, 2007). However, these results can be explained using the tripartite model of emotion (Clark \& Watson, 1991). For (positive) instructional and organizational teaching behavior, a previous study (Pössel, Rudasill, Adelson, et al., 2013) found negative associations of these teaching behaviors types with negative affect, but no associations with positive affect. Thus, in the current study, (positive) instructional and organizational teaching behavior may only be significantly associated with one of the two parts of depression as postulated by the tripartite model of emotion (Clark \& Watson, 1991). Thus, when measuring depression as one construct, the details of the associations between the parts of depression and these types of teaching behavior may get lost. If this hypothesis is correct, it is important to point out that these types of teaching behavior are important for students' negative affect, even if no significant associations with depressive symptoms could be found 
in this study. However, to test this hypothesis, a study measuring students' positive and negative affect along with depressive symptoms would be necessary.

\section{Teaching Behavior and Depressive Symptoms in Catholic Middle School Students}

Differing from the findings in the high school sample, both (positive) instructional teaching behavior and organizational teaching behavior, but not socio-emotional and negative teaching behavior, are significantly associated with depressive symptoms in the Catholic middle school sample. More specifically, (positive) instructional teaching behavior is negatively associated with depressive symptoms. Following from this, more (positive) instructional teaching behavior, such as making sure students understand the class material, using examples students will understand, and staying on task, is associated with fewer depressive symptoms in Catholic middle school students. As no data exist concerning the relationship of teaching behavior types with positive and negative affect in middle school students, the tripartite model of emotion (Clark \& Watson, 1991) cannot be used to explain the findings in this age group. However, the negative association between instructional teaching behavior and depressive symptoms is consistent with previous research on (positive) instructional teaching behavior and its relationships with academic and psychosocial outcomes (Curby et al., 2011; Hamre \& Pianta, 2005; Humensky et al., 2010; Pössel, Rudasill, Adelson, et al., 2013; Roeser et al., 2000; Rubie-Davies, 2007).

Based on previous research regarding organizational teaching behavior, depressive symptoms, affect, and academic outcomes (Bohn et al., 2004; Cameron et al., 2005; Pössel, Rudasill, Adelson, et al., 2013; Rimm-Kaufman et al., 2010; Rubie-Davies, 2007), it was unexpected to find that organizational teaching behavior is positively associated with depressive symptoms. Following from this, increasing organizational teaching behavior, such as making sure students understand the classroom rules and explaining to students why misbehavior is wrong, is associated with greater depressive symptoms in middle school 
students. Future research should be conducted in an attempt to replicate these findings, as well as consider other variables, to try to better understand this surprising finding. A possible explanation for the results may be that middle school students interpret organizational teaching behavior as teachers being critical of the students themselves, instead of critical of their behavior. For example, items that measure organizational teaching behavior such as, "My teacher takes away a privilege if I abuse it," could be interpreted in this way, resulting in a negative self-view; negative self-view is associated with depressive symptoms in 12- and 13-year-olds (Alloy et al., 2012). However, if this relationship is due to the students' interpretation of the teaching behavior in this way, one would expect to see a positive association between negative teaching behavior and depressive symptoms in middle school students as well. This would especially be expected as the Negative Teaching Behavior scale includes items such as, "My teacher threatens to punish me," which a student could also likely interpret as a critique on himself or herself. Further exploration in this area is needed.

\section{Implications for Practice}

Before considering the implications for practice of the present findings, similarities and differences between the presented approach to focus on teaching behavior of individual teachers and positive behavioral intervention and supports (PBIS) should be highlighted. Particularly organizational teaching behavior, which includes teaching behaviors related to management of student behavior, seems similar to PBIS. PBIS are strategies and expectations implemented in schools in order to both promote desirable and reduce problem behaviors in students, which in turn maintains a safe and successful school environment (e.g. Sugai et al., 2000; Lewis, Barrett, Sugai, \& Horner, 2010). However, there are differences between the two concepts as well. While PBIS is often implemented on a school- or even district-wide level (e.g. Flannery, Fenning, McGrath Kato, \& McIntosh, 2014; George \& Kincaid, 2008; Horner et al., 2009; Scott, 2001), teaching behavior, as measured by the TBQ, 
is focused on the individual level, specifically, the behaviors of an individual teacher.

Following from this, while PBIS often focuses on student behavioral outcomes from schoolor district-wide behavioral interventions or supports, teaching behavior, as measured by the TBQ, has been used to focus on how the teaching behavior of one specific teacher impacts the psychological outcomes (such as depressive symptoms) of many students based on the behavior of one specific teacher.

The present findings have important implications for school personnel, including teachers, school psychologists, and principals. School psychologists might want to help teachers be mindful of their teaching behavior, and possibly even change it. Of particular importance for school psychologists in high schools is to help teachers avoid negative teaching behavior by focusing on enacting consistent consequences for misbehavior and not letting their behavior be influenced by their emotions. Further, it is important to remember that (positive) instructional teaching behavior is associated with negative affect of high school students (Pössel, Rudasill, Adelson, et al., 2013) and depressive symptoms in middle school students. Thus, school psychologists in middle and high schools may want to help teachers in their school to make sure students understand the class material and to stay on task. School psychologists could use the findings from the study during consultation with teachers or when developing behavior modification programs for students. As research continues in this area, there is the possibility of preventing or reducing middle and high school student depressive symptoms by changing teacher behavior.

\section{Limitations of the Study}

A potential limitation regarding the generalizability of the findings is that in addition to the lack of ethnic diversity, all data were collected in private, Catholic schools. Due to the structure of the school around religion, Catholic schools can be distinctive from public, nonreligious schools. In a nationwide survey of administrators and teachers at Catholic schools 
(pre-kindergarten though grade 12), around 90\% of participants reported that the presence of a strong faith community, beginning the school day with prayer, and providing a course on Catholic teachings were all essential for a school's Catholic identity (Convey, 2012). However, Convey (2012) makes clear that representative sampling procedures were not used, and that the findings may not be generalizable to all Catholic schools. In the current study, data were collected from multiple Catholic schools, and information was not gathered regarding the specific involvement of Catholicism in their teaching practices. To add to this, one could assume that each of these schools may engage this doctrine in varying levels, making it hard to generalize the level of doctrine incorporated at each school.

The results of the current study could have been influenced if systematic differences between teaching behaviors in private, Catholic and public, non-religious schools or between students' interpretations of teaching behavior in both types of schools exist. However, we are not aware of research regarding such differences in teaching behavior between private Catholic and public, non-religious schools. In addition, the associations of teaching behavior with negative and positive affect that were found using a public high school sample (Pössel, Rudasill, Adelson, et al., 2013) and the associations of teaching behavior with depressive symptoms found in the current private high school sample form one common pattern explainable by the tripartite model of emotion (Clark \& Watson, 1991).

Another limitation is the cross-sectional design, which does not allow for conclusions about the directionality of the associations between teaching behavior and depressive symptoms. Thus, future longitudinal studies seem necessary. The sole utilization of selfreport instruments can be seen as another limitation of the present research. Especially as common method variance may result when the same individual provides information on all variables (e.g., Podsakoff, MacKenzie, Lee, \& Podsakoff, 2003). Thus, the use of multiple methods (e.g. teacher-reports or observations to measure teaching behavior) would be 
beneficial for future studies, incorporating an exploration of the gap between student-reported teaching behavior and teacher-report of their own behavior. This would build off of Pössel, Rudasill, Adelson, et al.'s (2013) finding that, while certain student-reported teaching behavior types did predict positive and/or negative affect, teacher-reported teaching behavior did not predict positive or negative affect. Nevertheless, it needs to be considered that even though gathering observations of teaching behavior is considered the gold standard, collection of these observations requires significant time and monetary resources (Douglas, 2009). In support of student report, some research suggests that student reports of teaching behavior is more valuable than other sources (Eccles et al., 1993; Pössel, Rudasill, Adelson, et al, 2013; Wubbels \& Levy, 1991). To add to this, gathering teacher reports of their own teaching behavior may not accurately reflect their behavior due to positive impression management or lack of insight (Douglas, 2009).

Related to this concern over accuracy is the use of self-report to measure depressive symptoms instead of using clinical interviews. However, previous studies have demonstrated that adolescents are a reliable source of information about their own depressive symptoms (Inderbitzen, 1994). In addition, depression measured by self-report has high predictive validity (Gotlib, Lewinsohn, \& Seeley, 1995). Nevertheless, additional information such as clinical interviews could be included in future research. 


\section{Acknowledgements}

We would like to thank the students and teachers involved in the data collection for making this project possible. 


\section{References}

Abela, J. R., \& Hankin, B. L. (2008). Handbook of depression in children and adolescents. New York, NY: Guilford Press.

Alloy, L. B., Shimrit, K. N., Young, M. E., Goldstein, K. E., Benjamin, G. S., Stange, J. P., ... Abramson, L. Y. (2012). Cognitive vulnerabilities and depression versus other psychopathology symptoms and diagnoses in early adolescence. Journal of Clinical Child \& Adolescent Psychology, 41, 539-560. doi: 10.1080/15374416.2012.703123

Barber, B. K., \& Olsen, J. A. (2004). Assessing the transitions to middle and high school. Journal of Adolescent Research, 19, 3-30. doi: 10.1177/0743558403258113

Bentler, P. M. (1990). Comparative fit indexes in structural models. Psychological Bulletin, 107, 238-246. doi: 0.1037/0033-2909.107.2.238

Bentler, P. M., \& Bonnet, D. C. (1980). Significance tests and goodness of fit in the analysis of covariance structures. Psychological Bulletin, 88, 588-606. doi: 10.1037/00332909.88.3.588

Blyth, D. A., Simmons, R. G., \& Carlton-Ford, S. (1983). The adjustment of early adolescents to school transitions. Journal of Early Adolescence, 3, 105-120. doi: $10.1177 / 027243168331008$

Bohn, C. M., Roehrig, A. D., \& Pressley, M. (2004). The first days of school in the classrooms of two more effective and four less effective primary-grades teachers. Elementary School Journal, 104, 269-287.

Cameron, C. E., Connor, C. D., \& Morrison, F. J. (2005). Effects of variation in teacher organization on classroom functioning. Journal of School Psychology, 43, 61-85. doi:10.1016/j.jsp.2004.12.002 
Cheung, S. (1995). Life events, classroom environment, achievement expectation, and depression among early adolescents. Social Behavior and Personality, 23, 83-92. doi: $10.2224 /$ sbp.1995.23.1.83

Clark, L. A., \& Watson, D. (1991). Tripartite model of anxiety and depression: Psychometric evidence and taxonomic implications. Journal of Abnormal Psychology, 100, 316-336. doi: 10.1037/0021-843X.100.3.316

Connor, C. M., Morrison, F. J., Fishman, B. J., Ponitz, C. C., Glasney, S., Underwood, P. S., Piasta, S. B., Crowe, E. C., \& Schatschneider, C. (2009). The ISI Classroom Observation System: Examining the literacy instruction provided to individual students. Educational Researcher, 38, 85-99. doi: 10.3102/0013189X09332373

Convey, J. (2012). Perceptions of Catholic identity: Views of Catholic school administrators and teachers. Catholic Education, 16, 187-214.

Croninger, R. G., \& Valli, L. (2009). "Where is the action?” Challenges to studying the teaching of reading in elementary classrooms. Educational Researcher, 38, 100-108. doi: 10.3102/0013189X09333206

Curby, T. W., Rudasill, K. M., Edwards, T., \& Perez-Edgar, K. (2011). The role of classroom quality in ameliorating the academic and social risks associated with difficult temperament. School Psychology Quarterly, 26, 175-188. doi: 10.1037/a0023042

Douglas, K. (2009). Sharpening our focus in measuring classroom instruction. Educational Researcher, 38, 518-521. doi: 10.3102/0013189X09350881

Eccles, J., Midgley, C., \& Adler, T. F. (1994). Grade-related changes in the school environment: Effects on achievement motivation. In J. G. Nicholls (Ed.), Advances in motivation and achievement (pp. 283-331). Greenwich, CT: JAI Press. 
Eccles, J. S., Midgley, C., Buchanan, C. M., Wigfield, A., Reuman, D., \& MacIver, D. (1993). Development during adolescence: The impact of stage/environment fit. American Psychologist, 48, 90-101.

Flannery, K. B., Fenning, P., McGrath Kato, M., \& McIntosh, K. (2014). Effects of a schoolwide positive behavioral interventions and supports and fidelity of implementation on problem behavior in high schools. School Psychology Quarterly, 29(2), 111-124. doi: 10.1300/J019v24n01_03

Furrer, C., \& Skinner, E. (2003). Sense of relatedness as a factor in children's academic engagement and performance. Journal of Educational Psychology, 95, 148-162. doi: 10.1037/0022-0663.95.1.148

Georgiades, K., Lewinsohn, P. M., Monroe, S. M., \& Seeley, J. R. (2006). Major depressive disorder in adolescence: The role of subthreshold symptoms. Journal of the American Academy of Child and Adolescent Psychiatry, 45, 936-944.

doi:10.1097/01.chi.0000223313.25536.47

George, H. P., \& Kincaid, D. K. (2008). Building district-level capacity for positive behavior support. Journal of Positive Behavior Interventions, 10, 20-32. doi: $10.1177 / 1098300707311367$

Gotlib, I. H., Lewinsohn, P. M., \& Seeley, J. R. (1995). Symptoms versus a diagnosis of depression: Differences in psychosocial functioning. Journal of Consulting and Clinical Psychology, 63, 90-100.

Hamre, B. K., \& Pianta, R. C. (2005). Can instructional and emotional support in the firstgrade classroom make a difference for children at risk of school failure? Child Development, 76, 949-967. doi:10.1111/j.1467-8624.2005.00889.x

Hankin, B. L., Abramson, L. Y., Moffitt, T. E., McGee, R., Silva, P. A., \& Angell, K. E. (1998). Development of depression from preadolescence to young adulthood: 
Emerging gender differences in a 10-year longitudinal study. Journal of Abnormal Psychology, 107, 128-140. doi: 10.1037/0021-843X.107.1.128

Hatcher, R., Hatcher, S., Berlin, M., Okla, K., \& Richards, J. (1990). Psychological mindedness and abstract reasoning in late childhood and adolescence: An exploration using new instruments. Journal of Youth and Adolescence, 19, 307-326. doi: 10.1007/BF01537075

Horner, R. H., Sugai, G., Smolkowski, K., Eber, L., Nakasato, J., Todd, A. W., \& Esperanza, J. (2009). A randomized, wait-list controlled effectiveness trial assessing school-wide positive behavior support in elementary schools. Journal of Positive Behavior Supports, 11, 133-144. doi:10.1177/1098300709332067

Hu, L., \& Bentler, P. M. (1999). Cut-off criteria for fit indexes in covariance structure analysis: Conventional criteria versus new alternatives. Structural Equation Modeling, 6, 1-55. doi: 10.1080/10705519909540118

Humensky, J., Kuwabara, S. A., Fogel, J., Wells, C., Goodwin, B., \& Van Voorhees, B. W. (2010). Adolescents with depressive symptoms and their challenges with learning in school. The Journal of School Nursing, 26, 377-392. doi: $10.1177 / 1059840510376515$

Inderbitzen, H. M. (1994), Adolescent peer social competence. A critical review of assessment methodologies and instruments. In T. H. Ollendick \& R. J. Prinz (Eds.), Advances in clinical child psychology (pp. 227-259). New York, NY: Springer.

Jonsson, U., Bohman, H., Hjern, A., von Knorring, L., Olsson, G., \& von Knorring, A. L. (2010). Subsequent higher education after adolescent depression: A 15-year follow-up register study. European Psychiatry, 25, 396-401. doi: 10.1016/j.eurpsy.2010.01.016 
Klein, D. N., Torpey, D. C., \& Bufferd, S. J. (2008). Depressive disorders. In T. P. Beauchaine \& S. P. Hinshaw (Eds.), Child and adolescent psychopathology (pp. 477509). Hoboken, NJ: Wiley.

Kline, R. B. (2005). Principals and practice of structural equation modeling ( $2^{\text {nd }}$ ed.). New York, NY: Guilford.

Lewis, T. J., Barrett, S., Sugai, G., \& Horner, R. H. (2010). Blueprint for schoolwide positive behavior support training and professional development. Retrieved from www.pbis.org.

Lynch, M., \& Cicchetti, D. (1997). Children's relationships with adults and peers: An examination of elementary and junior high school students. Journal of School Psychology, 55, 81-99. doi 10.1016/S0022-4405(96)00031-3

Marini, Z., \& Case, R. (1994). The development of abstract reasoning about the physical and social world. Child Development, 65, 147-159.

Mash, E. J., \& Barkley, R. A. (Eds.). (2006). Treatment of childhood disorders. New York, NY: Guilford Press.

Meade, A. W., Johnson, E. C., \& Braddy, P. W. (2008). Power and sensitivity of alternative fit indices in tests of measurement invariance. Journal of Applied Psychology, 93, 568-592. doi: 10.1037/0021-9010.93.3.568

Mezulis, A., Funasaki, K., \& Hyde, J. S. (2011). Negative cognitive style trajectories in the transition to adolescence. Journal of Clinical Child and Adolescent Psychology, 40, 318-331. doi: 10.1080/15374416.2011.546048

Perry, K. E., Donohue, K. M., \& Weinstein, R. S. (2007). Teaching practices and the promotion of achievement and adjustment in first grade. Journal of School Psychology, 45, 269-292. doi: 10.1016/j.jsp.2007.02.005 
Pianta, R. C., \& Hamre, B. K. (2009). Conceptualization, measurement, and improvement of classroom processes: Standardized observation can leverage capacity. Educational Researcher, 38, 109-119. doi: 10.3102/0013189X09332374

Pianta, R. C., LaParo, K. M., \& Hamre, B. K. (2008). Classroom assessment scoring system. Baltimore, MD: Brookes.

Podsakoff, P., MacKenzie, S., Lee, J., \& Podsakoff, N. (2003). Common method biases in behavioral research: A critical review of the literature and recommended remedies. Journal of Applied Psychology, 88, 879-903.

Pössel, P., Rudasill, K. M., Adelson, J. L., Bjerg, A. C., Wooldridge, D. T., \& Winkeljohn Black, S. (2013). Teaching behavior and well-being in students: Development and concurrent validity of an instrument to measure student-reported teaching behavior. International Journal of Emotional Education, 5, 5-30.

Pössel, P., Rudasill, K. M., Sawyer, M. G., Spence, S. H., \& Bjerg, A. C. (2013). Associations between teacher support and depression in Australian adolescents: A 5year longitudinal study. Developmental Psychology, 49, 2135-2146. doi: $10.1037 / \mathrm{a} 0031767$

Radloff, L. S. (1977). The CES-D scale: A self-report depression scale for research in the general population. Applied Psychological Measurement, 1, 385-401. doi: $10.1177 / 014662167700100306$

Raudenbush, S., Bryk, A., Cheong, Y. F., Congdon, R., \& du Toit, M. (2004). HLM6: Hierarchical linear and non-linear modeling. Lincolnwood, IL: Scientific Software International.

Reddy, R., Rhodes, J., \& Mulhall, P. (2003). The influence of teacher support on student adjustment in the middle school years: A latent growth curve study. Development and Psychopathology, 15, 119-138. doi: 10.1017.S0954579403000075 
Rimm-Kaufman, S. E., Early, D. M., Cox, M. J., Saluja, G., Pinata, R. C., Bradley, R. H., Payne, C. (2002). Early behavioral attributes and teachers' sensitivity as predictors of competent behavior in the kindergarten classroom. Applied Developmental Psychology, 23, 451-470. doi: 10.1016/S0193-3973(02)00128-4

Roberts, R. E., Andrews, J. A., Lewinsohn, P. M., \& Hops, H. (1990). Assessment of depression in adolescents using the Center for Epidemiologic Studies Depression Scale. Psychological Assessment, 2, 122-128. doi: 10.1037/1040-3590.2.2.122

Roeser, R. W., \& Eccles, J. S. (1998). Adolescents' perceptions of middle school: Relation to longitudinal changes in academic and psychological adjustment. Journal of Research on Adolescence, 8, 123-158. doi: 10.1207/s15327795jra0801_6

Roeser, R., Eccles, J.S., \& Sameroff, A. J. (2000). School as a context of early adolescents' academic and social-emotional development: A summary of research findings. Elementary School Journal, 100, 443-471. doi: 10.1086/499650

Roeser, R., Midgley, C., \& Urdan, T. (1996). Perceptions of the school psychological environment and early adolescents' psychological and behavioral functioning in school: The mediating role of goals and belonging. Journal of Educational Psychology, 88, 408-422. doi: 10.1037/0022-0663.88.3.408

Rubie-Davies, C. M. (2007). Classroom interactions: Exploring the practices of high- and low-expectation teachers. British Journal of Educational Psychology, 77, 289306. doi :10.1348/000709906X101601

Rudasill, K. M., Gallagher, K., \& White, J. M. (2010). Temperamental attention and activity, classroom emotional support, and academic achievement in third grade. Journal of School Psychology, 48, 113-134. doi: 10.1016/j.jsp.2009.11.002

Rutter, M. (1982). Fifteen thousand hours: Secondary schools and their effects on children. Harvard University Press. 
Rutter, M., Caspi, A., \& Moffitt, T. E. (2003). Using sex differences in psychopathology to study causal mechanisms: Unifying issues and research. Journal of Child Psychiatry and Psychology, 44, 1092-1115. doi: 10.1111/1469-7610.00194

Ryan, A. M., \& Shim, S. S. (2012). Changes in help seeking from peers during early adolescence: Associations with changes in achievement and perceptions of teachers. Journal of Educational Psychology, 104, 1122-1134. doi: 10.1037/a0027696

Ryan, R., Stiller, J., \& Lynch, J. (1994). Representations of relationships to teachers, parents, and friends as predictors of academic motivation and self-esteem. Journal of Early Adolescence, 14, 226-249. doi: 10.1177/027243169401400207

Somersalo, H., Solantaus, T., \& Almqvist, F. (2002). Classroom climate and the mental health of primary school children. Nordic Journal of Psychiatry, 56, 285-290. doi: $10.1080 / 08039480260242787$

Steiger, J. H., \& Lind, J. M. (1980, May). Statistically based tests for the number of common factors. Paper presented at the meeting of Psychometrika Society, Iowa City, IA.

Soar, R. S., \& Soar, R. M. (1987). Classroom management and affect expression. Professional School Psychology, 2, 3-14. doi: 10.1037/h0090529

Scott, T. M. (2001). A schoolwide example of positive behavioral support. Journal of Positive Behavior Interventions, 3, 88-94. doi: 10.1177/109830070100300205

Sugai, G., Horner, R. H., Dunlap, G., Hieneman, M., Lewis, T. J., Nelson, C. M. .. Ruef, M. (2000). Applying positive behavior support and functional behavioral assessment in schools. Journal of Positive Behavior Interventions, 2, 121-143. doi: $10.1177 / 109830070000200302$

Ullman, J. B. (1996). Structural equation modeling. In B. Tabachnick \& L. Fidell (Eds.), Using multivariate statistics (pp. 709-812). New York, NY: HarperCollins. 
Wentzel, K. R. (2002). Are effective teachers like good parents? Interpersonal predictors of school adjustment in early adolescence. Child Development, 73, 287-301. doi: $10.1111 / 1467-8624.00406$

Wubbels, T., \& Levy, J. (1991). A comparison of interpersonal behavior of Dutch and American teachers. International Journal of Intercultural Relations, 15, 1-18. 
Table 1

Intercorrelations, Internal Consistencies, and Descriptives of TBQ scales and CES-D for High School and Middle School Samples

\begin{tabular}{|c|c|c|c|c|c|}
\hline & Inst & $\mathrm{Neg}$ & Socio & Org & CES-D \\
\hline \multicolumn{6}{|c|}{ High school students $(n=976)$} \\
\hline Inst & .97 & & & & \\
\hline Neg & $.32 * *$ & .88 & & & \\
\hline Socio & $.75^{* *}$ & $.42 * *$ & .93 & & \\
\hline Org & $.75^{* *}$ & $.43^{* *}$ & $.67 * *$ & .87 & \\
\hline CES-D & $.15 * * *$ & $.31 * * *$ & $.16^{* * *}$ & $.24 * * *$ & .93 \\
\hline Mean \pm SD & $3.16 \pm 0.92$ & $1.60 \pm 0.65$ & $2.40 \pm 0.87$ & $2.74 \pm 0.91$ & $21.74 \pm 15.07$ \\
\hline \multicolumn{6}{|c|}{ Middle school students $(n=763)$} \\
\hline Inst & .97 & & & & \\
\hline Neg & $.47 * *$ & .92 & & & \\
\hline Socio & $.79 * *$ & $.58 * *$ & .95 & & \\
\hline Org & $.81 * *$ & $.64 * *$ & $.76^{* *}$ & .90 & \\
\hline CES-D & $.24 * * *$ & $.17 * * *$ & $.21 * * *$ & $.26 * * *$ & .92 \\
\hline Mean \pm SD & $2.85 \pm 1.10$ & $1.71 \pm 0.86$ & $2.07 \pm 0.97$ & $2.61 \pm 1.13$ & $17.67 \pm 14.70$ \\
\hline \multicolumn{6}{|c|}{ Note. Cronbach's alphas are represented in the diagonal, Inst $=$ (Positive) Instructional } \\
\hline \multicolumn{6}{|c|}{ Behavior, Neg $=$ Negative Teaching Behavior, Socio $=$ Socio-Emotional Behavior, Org $=$} \\
\hline
\end{tabular}


Table 2

Estimated Fixed Effects of the TBQ Scales on the CES-D Scale in the Middle School and the High School Samples

Parameter Parameter estimate SE

High school students $(n=976)$

(Positive) Instructional Behavior $\left(\gamma_{10}\right)$

$-0.738$

1.397

Negative Teaching Behavior $\left(\gamma_{20}\right)$

$3.206^{*}$

Socio-Emotional Behavior $\left(\gamma_{30}\right)$

1.285

1.133

Organizational Behavior $\left(\gamma_{40}\right)$

1.196

0.970

Middle school students $(n=763)$

(Positive) Instructional Behavior $\left(\gamma_{10}\right)$

$-2.412 *$

1.117

Negative Teaching Behavior $\left(\gamma_{20}\right)$

$-0.726$

1.210

Socio-Emotional Behavior $\left(\gamma_{30}\right)$

1.257

1.503

Organizational Behavior $\left(\gamma_{40}\right)$

$2.217 * *$

0.763

Note. $* p<.05 ; * * p<.01$. 